Proceedings of the 33rd Annual Meeting of the Brazilian Embryo Technology Society (SBTE); Ilha de Comandatuba, BA, Brazil, August 15th to 19th, 2019.

\title{
Aspects of embryo-maternal communication in establishment of pregnancy in cattle
}

\author{
José M. Sánchez, Constantine A. Simintiras, Patrick Lonergan*
}

School of Agriculture and Food Science, University College Dublin, Belfield, Dublin 4, Ireland.

\begin{abstract}
Establishment of pregnancy in mammals requires reciprocal molecular communication between the conceptus and endometrium that modifies the endometrial transcriptome and uterine luminal milieu to support pregnancy. Due to the small size of the early embryo and elongating conceptus relative to the volume of the uterine lumen, collection of endometrium adjacent to the developing conceptus is difficult following conventional uterine flushing methods in cattle. Use of endometrial explants in culture can overcome this challenge and reveal information about the dialogue between the developing embryo and the uterus. The aim of this short review is to summarize some of our recent findings in relation to embryo maternal interaction during bovine pregnancy establishment and to put them in the wider context of fertility in cattle.
\end{abstract}

Keywords: conceptus, fertility, bovine, uterus, progesterone.

\section{Introduction}

Embryo mortality is a major contributor to poor reproductive efficiency in dairy and beef cows. A significant proportion of embryonic loss in cattle, particularly lactating dairy cows, occurs during the first 2-3 weeks after conception, before maternal recognition of pregnancy, which occurs around Day 16. In a recent comprehensive review, Wiltbank et al. (2016) described four pivotal periods of pregnancy loss during the first trimester of gestation and discussed possible causes for pregnancy failure during these periods. Despite a relatively high fertilization rate (>85\%), $20 \%-50 \%$ of high-producing lactating dairy cows experience pregnancy loss during the first week of gestation. From Days 8 to 27, concomitant with embryo elongation and maternal recognition of pregnancy, losses average approximately 30\%. From Days 28 to 60, losses of approximately $12 \%$ occur while in the fourth period, during the third month of pregnancy, pregnancy losses are reduced (approximately 2\%), but may be elevated in some cows, particularly in those carrying twins in the same uterine horn (Wiltbank et al., 2016).

Communication between the developing embryo and the mother is vital for the successful establishment and maintenance of pregnancy but the requirement for this dialogue is temporal in nature and in reality only becomes absolutely essential from around Day 15-16 onwards. Pregnancies are routinely established in commercial embryo transfer following the transfer of 6-7 day old embryos, often produced in vitro, to synchronized recipients. Indeed, pregnancy can be established following the transfer of elongated conceptuses up to at least Day 16 (Betteridge et al., 1980; Kimura and Matsuyama 2014) indicating that the uterus does not need to receive any signals from the embryo prior to that stage in order for pregnancy occur.

Up to the blastocyst stage (Day 7-8), the bovine embryo is relatively autonomous, as blastocysts can be produced in vitro in the absence of contact with the female reproductive tract and are capable of establishing pregnancy after transfer to a synchronous uterus. In contrast to primates and rodents, in which implantation occurs shortly after the blastocyst enters the uterus, in ungulates, such as ruminants and pigs, the early conceptus undergoes a phase of rapid growth and elongation before implantation, the latter occurring 2-3 weeks after fertilization. In cattle, conceptus elongation is initiated around Day 13 of gestation when the hatched bovine blastocyst transitions sequentially from a spherical- to ovoid-, then tubular- and finally filamentous-shaped structure that primarily involves proliferation of the conceptus trophectoderm cells. During this time, the elongating conceptus secretes interferon tau (IFNT), the maternal pregnancy recognition signal in ruminants (Bazer and Thatcher 2017). While there is a strong positive correlation between conceptus length and IFNT secretion (Rizos et al., 2012), surprisingly, threshold concentrations of IFNT required to overcome luteolysis are as yet not known (Forde and Lonergan 2017; Spencer et al., 2017).

Elongation is necessary to ensure sufficient concentrations of IFNT are secreted and to expand the conceptus surface area for maximal vascular exchange with maternal tissues after implantation. An inability of the conceptus to optimally elongate undoubtedly results in embryonic loss and is believed to significantly contribute to reproductive failure in cattle (Wiltbank et al., 2016; Moraes et al., 2018). In contrast to prehatching development, elongation is predominantly maternally-driven, dependent on substances in the uterine lumen fluid (ULF; or histotroph). As evidence for this, blastocysts do not elongate in vitro (Brandão et al., 2004) and the absence of uterine glands in vivo results in failure of blastocysts to elongate following embryo transfer (Gray et al., 2002).

Spatial and temporal changes of the endometrial transcriptome and histotroph composition are necessary to establish uterine receptivity to implantation and, in turn, are pivotal to the likelihood of successful pregnancy in cattle. Those modifications are 
primarily regulated by the steroid hormone progesterone (P4) derived from the corpus luteum (CL) which acts via the endometrium to promote conceptus growth and implantation, as well as conceptus-derived IFNT, which prevents development of the endometrial luteolytic mechanism (Forde and Lonergan 2012; Brooks et al., 2014). The role of P4 in uterine receptivity is unequivocal (Lonergan et al., 2016; Spencer et al., 2016). Low circulating P4 concentrations in the first week after ovulation, as frequently occurs in highproducing lactating dairy cows, are associated with under-developed conceptuses (Forde et al., 2012) with an altered transcriptomic signature (Barnwell et al., 2016) and a low likelihood of establishing pregnancy (Wiltbank et al., 2016). On the other hand, elevated concentrations of circulating $\mathrm{P} 4$ in the period immediately after conception have been associated with advanced conceptus elongation (Carter et al., 2008), increased IFNT production (Mann and Lamming 2001), and greater pregnancy rates in cattle and sheep (Ashworth et al., 1989; Stronge et al., 2005; McNeill et al., 2006). Despite the definitive association between P4 and conceptus elongation, significant natural variation in age-matched in vivo- (Betteridge et al., 1980) and in vitro-derived conceptuses occurs, even amongst conceptuses developing in the same uterus (Clemente $e t$ al., 2009; Sánchez et al., 2019a; b). This would suggest that part of the ability to elongate is intrinsic to the embryo and may be related to oocyte and/or blastocyst quality.

The aim of this short review is to summarize some of our recent findings in relation to embryo maternal interaction during bovine pregnancy establishment and to put them in the wider context of fertility in cattle. Several of the recent studies referred to below have used an endometrial explant co-culture system to elucidate this fine dialogue by examining changes in endometrial gene expression induced by blastocysts (Passaro et al., 2018, 2019) or by an elongating conceptus (Mathew et al., 2019; Sánchez et al., 2019b; Bagés-Arnal et al., 2019). Due to the maintenance of normal cellular and extracellular architecture in endometrial explants (Borges et al., 2012), some of the limitations of traditional cell culture can be overcome; for example, uterine explants allow the communication between resident populations of endometrial cells which cannot be achieved with current 2D and 3D cell culture technologies.

\section{Role of progesterone in uterine receptivity and conceptus elongation}

Progesterone from the CL induces both temporal and spatial changes in the endometrial transcriptome necessary to establish uterine receptivity, when implantation in the uterus is possible (Forde et al., 2009). These changes include down-regulation of the nuclear progesterone receptor (PGR) in the luminal and then glandular epithelium (Okumu et al., 2010), which allows expression of genes and secretion of their protein products, as well as active transport of other molecules, required for conceptus elongation.
The capacity of the uterus to stimulate conceptus elongation is primarily dependent on secretions from the luminal and glandular epithelium. However, the timing of conceptus elongation is clearly associated with concentrations of $\mathrm{P} 4$ in circulation, which acts via the uterus (Clemente et al., 2009) to alter the timing of PGR downregulation and thus onset of expression of key genes required for elongation in cattle (Forde et al., 2009) and sheep (Satterfield et al., 2006). Consequently, P4 has an indirect effect on the secretion of IFNT by the conceptus, given the strong positive correlation between conceptus length and IFNT production (Rizos et al., 2012). In order for P4 output from the CL to be maintained, sufficient quantities of IFNT must be produced by the conceptus by Day 16 to abrogate the luteolytic mechanism and maintain CL function and induce expression of both classical and nonclassical interferon-stimulated genes (ISG) in the different cellular compartments of the endometrium that are proposed to regulate conceptus elongation.

Temporal changes in uterine gene expression occur irrespective of whether the cow is pregnant or not (Forde et al., 2009) and it is only during maternal recognition of pregnancy, around Day 16, by which time the conceptus is secreting copious amounts of IFNT (Forde and Lonergan 2017) that major changes in gene expression between cyclic and pregnant endometrium become apparent (Forde et al., 2011; Bauersachs et al., 2012).

\section{Blastocyst-induced changes in the endometrium}

Pregnancy recognition in cattle is initiated around Day 15-16, both at the physiological and transcriptomic level. Nonetheless, the first week of development is critical as evidenced by the fact that, at least in high-producing dairy cows, about $50 \%$ of embryos are no longer viable by Day 6-7 (Sartori et al., 2010). Whether communication between the embryo and endometrium at this stage is really important remains to be demonstrated convincingly. There is unequivocal evidence that when development occurs in vivo, blastocyst quality is improved in terms of ultrastructure (Rizos et al., 2002a), gene expression profiles (Lonergan et al., 2003a, b; Gad et al., 2012), cryotolerance (Rizos et al., 2002b) and pregnancy rate after transfer (Hasler et al., 1995) compared to when blastocysts are produced in vitro. However, evidence of a reciprocal effect of a single embryo on the cells of the uterus is more difficult to detect. As mentioned earlier, the fact that blastocysts can be produced routinely in vitro in the absence of contact with the reproductive tract and subsequently establish a pregnancy after transfer to a recipient supports the notion that exposure of the reproductive tract to the early embryo, or viceversa, is not required for pregnancy.

In vitro studies have demonstrated that preimplantation embryos secrete a variety of biochemical messengers, embryotropins, that act in an autocrine manner to promote embryonic development (reviewed by Wydooghe et al., 2015). For many of these factors, expression of corresponding receptors in 
the uterus has been identified, the activation of which could lead to cellular and tissue responses in regions that are in close physical contact with the embryo. Others have reported that the early bovine embryo (from Day 5 to Day 9) induces an anti-inflammatory response in uterine epithelial cells and immune cells in vitro (Talukder et al., 2017). Therefore, if factors secreted by the pre-elongating embryo enhance changes in the transcriptome and in the proteome of the endometrium, those changes are most likely to be local in nature and may not be detectable using crude methods of sample collection. Use of an explant model allows the interrogation of cells that were in direct contact with the embryo(s) facilitating the detection of such local embryo-induced changes in the endometrium during the very early stages of pregnancy.

Recently, local embryo-induced alterations in the endometrial transcriptome from spatially-defined regions in response to the presence of a Day 7 bovine embryo were reported (Sponchiado et al., 2017). In that study, the presence of an embryo altered the abundance of 12 transcripts in the cranial part of the uterine horn ipsilateral to the CL, including classical ISG (ISG15, $M X 1, M X 2, O A S 1 Y$ ), genes involved in prostaglandin biosynthesis (PTGES, HPGD, AKR1L4), water channels (AQP4) and a solute transporter (SLC1A4); however, the extent of change was relatively minor in nature ranging from 1.35- to 2-fold). Based on this, we hypothesized that the blastocyst induces local changes in the endometrial transcriptome through the production of IFNT and potentially other diffusible factors. Using co-culture of endometrial explants in the absence or presence of blastocysts or medium conditioned by blastocysts, we demonstrated that bovine endometrium responds to the presence of 8-day old blastocysts by upregulating expression of classical ISG (Passaro et al., 2018). This effect was (i) specific to the blastocyst stage - earlier stages did not induce gene expression changes, (ii) dependent on the number of blastocysts present - a minimum of 5 blastocysts were required to detect such changes, and (iii) independent of direct contact - the effect was induced by embryos co-cultured on endometrial explants using a cell culture insert (preventing direct contact) as well as by blastocystconditioned medium (Passaro et al., 2018). While others have reported differential expression of a small number of other transcripts in the endometrium in vivo, induced by the presence of a single blastocyst (Sponchiado et al., 2017), or in cultured endometrial cells (Talukder et al., 2017; Gómez et al., 2018), we failed to detect in endometrial explants using qPCR (Passaro et al., 2018).

To extend these findings, Passaro et al. (2019) used RNA sequencing to investigate global changes in the transcriptome of endometrial explants induced by exposure to blastocysts. Exposure of bovine endometrium to blastocyst-stage embryos resulted in the upregulation of 40 transcripts in blastocyst-exposed endometrial explants compared to the control. Comparison of this list of differentially expressed genes (DEG) with the common list of genes altered in endometrial explants following culture with $100 \mathrm{ng} / \mathrm{ml}$ IFNT or a Day 15 conceptus (from Sánchez et al., 2019b; Fig. 1) indicated that all of the DEG induced in the endometrium by blastocyst-stage embryos are IFNT-stimulated, in contrast to Day 15 when a significant number of IFNT-independent genes are induced (Mathew et al., 2019; Sánchez et al., 2019b see below).

These results support the concept that the early embryo is capable of communicating with the reproductive tract. The effect on the endometrial transcriptome is dependent on the stage of embryo development and appears to be due solely to IFNT. The functional significance, if any, of such induced changes remains to be fully elucidated given that it is possible to transfer embryos from Day 7 onwards to a uterus that has not previously been exposed to an embryo and achieve normal pregnancy rates.

\section{Response of the endometrium to in vivo or in vitro derived conceptuses}

It has been elegantly shown that the endometrium can act as a 'sensor', with its transcriptome reflective of the type and developmental competency of the conceptus present (Bauersachs et al., 2009; Mansouri-Attia et al., 2009). These studies compared the endometrial responses to bovine conceptuses produced by somatic cell nuclear transfer, in vitro fertilization or artificial insemination (AI) and suggested that placental failure in bovine clone pregnancies may originate from abnormal embryomaternal communication during the peri-implantation period (Day 18-20).

As stated above, it is generally accepted that blastocysts produced in vitro are inferior in quality to in vivo-derived embryos. This difference is reflected in the fact that in commercial embryo transfer, the majority of in vitro-produced blastocysts are transferred fresh while the majority of in vivo-derived blastocysts are transferred frozen (Viana, 2018).

Mathew et al. (2019) compared the transcriptomic response of the endometrium following exposure to IFNT or a conceptus derived from the transfer of an in vivo-derived (superovulation and AI) or in vitro-produced (IVF) blastocyst in order to identify novel transcripts dependent and independent on IFNT, conceptus origin and conceptus sex. IVF- or AIproduced blastocysts were transferred into recipient heifers on Day 7 of the estrous cycle. On Day 15, IVFor AI-derived conceptuses were obtained by uterine flushing and individually placed on endometrial explants in media for $6 \mathrm{~h}$. Explants were also cultured with media alone as a control or media containing 100 $\mathrm{ng} / \mathrm{mL}$ recombinant ovine IFNT. Incubation of endometrium with IFNT or IVF- or AI-derived conceptuses altered the expression of 491, 498 and 576 transcripts, respectively, compared to the control. Further, 369 DEG were common between explants exposed to IFNT or a conceptus. 240 DEG were uniquely altered by conceptuses (IVF- and AI-derived) but not IFNT. Of these transcripts, 46 were shared between the IVF and AI groups, while 61 and 133 were specific to IVF and AI conceptuses, respectively. Five 
genes (MLPH, PROM2, MYADM, VN1R4L, HTR1A) were more abundant in endometrium exposed to female compared to male conceptuses while a single gene $(A R L 4 C)$ was more abundant in response to male conceptuses than female conceptuses.

These data support the hypothesis that conceptus regulation of gene expression in the endometrium is complex and involves factors other than IFNT that may have a biological role in pregnancy establishment. The findings are consistent with the presence of unique proteins in ULF of pregnant heifers on Day 16 and produced by short-term in vitro cultured Day 16 conceptuses (Forde et al., 2015) and those of Bartol et al. (1985) who demonstrated that the fully elongated bovine conceptus produces a significant number of proteins when cultured in vitro. Further, Spencer et al. (2013) demonstrated that the bovine conceptus produces prostaglandins, which can modify the endometrium prior to pregnancy recognition.

\section{Effect of conceptus length on the endometrial response}

Significant variation in the length and morphology of age-matched conceptuses exists, even when multiple conceptuses are recovered from the same uterine environment (Clemente et al., 2009; O’Hara et al., 2014), despite the fact that embryos were produced in vitro under the same conditions until the blastocyst stage and were of similar morphological quality at the time of transfer on Day 7. Conceptus length on a given day in the period around pregnancy recognition is thought to be indicative of its quality and the likelihood of establishing and maintaining a pregnancy (Barnwell et al., 2016), although this has yet to be definitively established. While significant differences in the transcriptomes of long and short Day 15 conceptuses have been reported (Barnwell et al., 2016), the interaction between such divergent conceptuses and the endometrium had, until recently, not been described. We hypothesized that bovine endometrium exposed to long vs. short Day 15 conceptuses would exhibit a different transcriptome profile reflective of potential for successful pregnancy establishment. To test this hypothesis we used a combination of in vitro production of bovine blastocysts, multiple embryo transfer and conceptus-endometrial explant co-culture to investigate the response of the endometrium to age-matched conceptuses of different sizes collected from the same uterine environment (Sánchez et al., 2019b). The main findings were that: (i) Day 15 conceptuses vary significantly in length, even when derived from the same uterine environment; and (ii) the endometrium responds in an IFNT-dependent and independent manner to conceptuses of different sizes which likely reflects the ability to successfully establish pregnancy (Fig. 1). These data complement nicely the data on the conceptus transcriptome mentioned above describing differential patterns of mRNA expression between short (mean length of $4.2 \pm 0.1 \mathrm{~mm})$ and long $(24.7 \pm 1.9 \mathrm{~mm}$ ) bovine conceptuses recovered on Day 15 of gestation (Barnwell et al., 2016). In that study, a total of 348 genes were differentially expressed related to metabolism and biosynthesis. These genes and cellular pathways involved in enhanced conceptus elongation, as well as the endometrial response blueprint to short and long conceptuses (Sánchez et al., 2019b), may ultimately serve as markers of successful pregnancy.

Whether or not smaller conceptuses on a given day are actually abnormal or whether they are simply slower in development is unclear; however, it is likely that they are compromised compared to longer (normal) conceptuses. Definitive proof will come from the recovery and retransfer of long and short age-matched conceptuses to establish their ability to initiate and maintain pregnancy.

While the differences in conceptus length are due, at least in part, to intrinsic differences in the embryo/conceptus, likely related to oocyte quality, it would be wrong to completely discount a role for the uterus in contributing to variation in conceptus length and pregnancy establishment. Using a model of repeated embryo transfer originally described by McMillan et al. (1999), Geary et al. (2016) classified heifers based on pregnancy success following serial embryo transfer as high fertile (HF), subfertile (SF), or infertile (IF). Conceptus survival and growth to Day 14 was not compromised in SF and IF heifers. However, pregnancy rate on Day 28 was higher in HF (70.4\%) than in heifers with low fertility (36.8\%; SF and IF). In a follow-up study (Moraes et al., 2018), pregnancy rate on Day 17 was substantially higher in HF (71\%) and SF (90\%) than IF (20\%) heifers. Furthermore, elongating conceptuses were about twofold longer in HF than SF heifers. Taken together, these data suggest that the uterus impacts conceptus survival and programs conceptus development, and effects of dysregulated conceptus-endometrial interactions elicit loss of the post-elongation conceptus in SF cattle during the implantation period of pregnancy.

In summary, bovine endometrium responds differently in terms of its gene expression signature to age-matched long and short conceptuses, in an IFNTdependent and independent manner, which may be critical for embryo survival. In particular, short conceptuses failed to alter the expression of a large number of ISG that were altered by both IFNT and long conceptuses, suggesting that insufficient IFNT production is a major contributory factor to lower survival of such conceptuses. Furthermore, the alteration of $>100$ endometrial transcripts uniquely by long conceptuses suggests that other aspects of maternal-embryo communication at this critical time are IFNT-independent. 


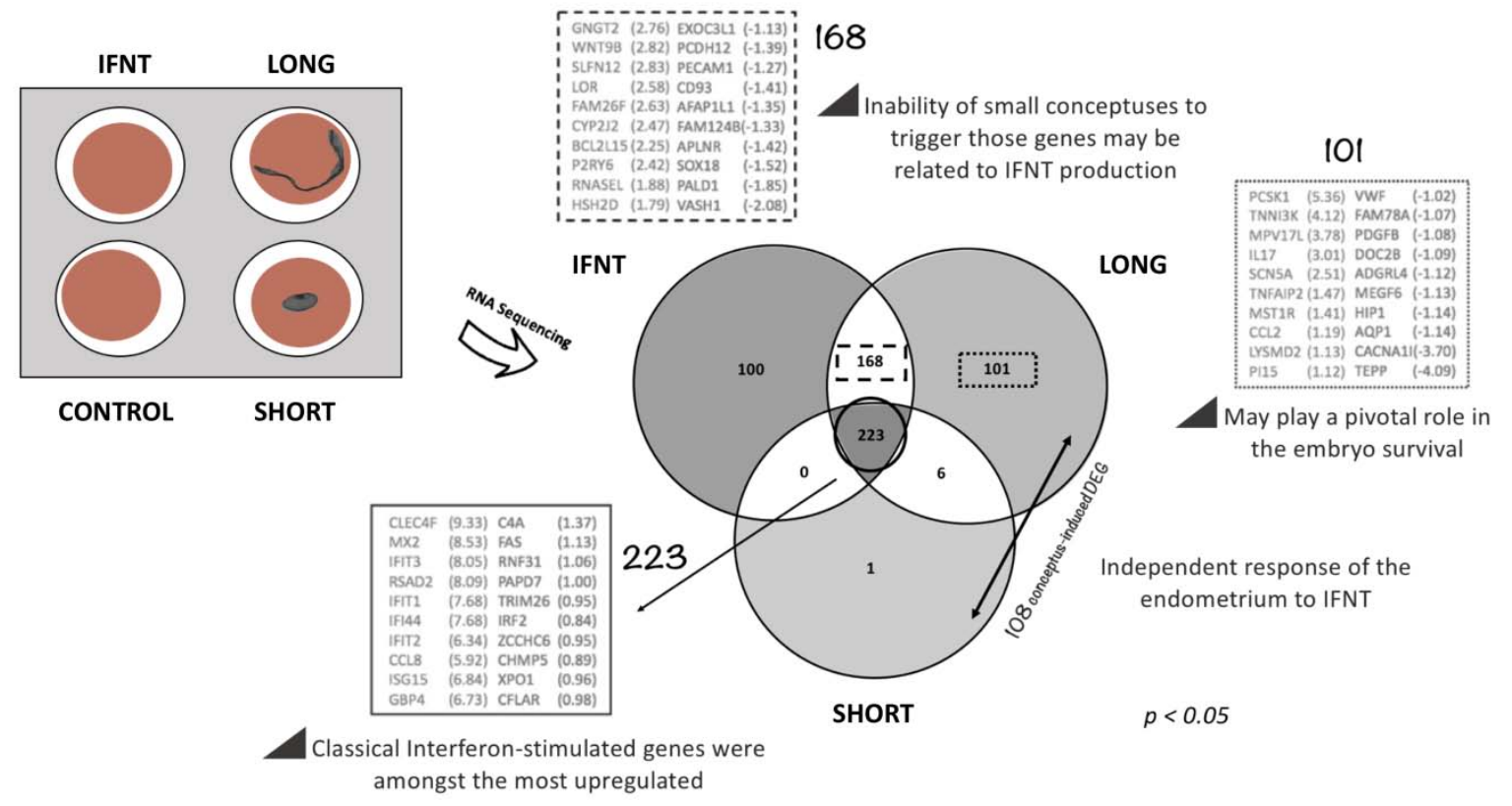

Figure 1. Use of an ex-vivo uterine endometrial explant-conceptus co-culture system to elucidate conceptus-induced effects on the endometrium both dependent and independent of interferon-tau (IFNT). Uterine explants taken from the same uterus were exposed to (i) medium alone (control), (ii) $100 \mathrm{ng} / \mathrm{ml}$ recombinant ovine IFNT, (iii) a long Day 15 conceptus, or (iv) a short Day 15 conceptus. Numbers of differentially expressed genes indicated for each group are relative to the Control. Modified from Sánchez et al. (2019b).

\section{Differential response of endometrium ipsilateral and contralateral to the $\mathbf{C L}$}

Embryo transfer studies established that the incidence of embryo loss is higher following transfer to the uterine horn contralateral to the ovary containing the CL compared to transfer to the ipsilateral horn (Christie et al., 1979). Whether these differences are manifest in conceptus growth and elongation in the critical window preceding maternal recognition of pregnancy is unknown. Knowledge of differences in gene expression between the uterine horns during the estrous cycle could further enhance our understanding of uterine receptivity and the process of conceptus elongation, key events for the maternal recognition of pregnancy and, in turn, successful pregnancy establishment.

We hypothesized that differences in the endometrial transcriptome between the ipsilateral and contralateral horns throughout the cycle exist, and those differences would be correlated with differences in conceptus elongation after embryo transfer (Sánchez et al., 2019a). Endometrial samples from both horns were collected from synchronized heifers slaughtered on Day $5,7,13$ or 16 post-estrus and subjected to RNA sequencing. Main findings were that: (i) day of the estrous cycle contributed to the greatest variation in the endometrial transcriptome; (ii) there were many more altered genes between the uterine horns ipsilateral and contralateral to the CL in the early (Day 5 and 7) as compared to late (Day 13 and 16) luteal phase; (iii) signalling pathways regulating pluripotency of stem cells were highly dysregulated when both uterine horns were compared, regardless of the day of luteal phase. In a separate experiment within the same study, ten Day 7 in vitro produced blastocysts were transferred into the uterine horn ipsilateral or contralateral to the CL or into both horns (i.e., bilateral) of synchronized recipient heifers. Reproductive tracts were recovered at slaughter on Day 14 and the number and dimensions of recovered conceptuses were recorded for each horn. Site of embryo transfer did not affect recovery rate (48.0\%, $168 / 350$ ) or length of conceptuses. Thus, although differences in gene expression exist between the endometrium of uterine horns ipsilateral and contralateral to the CL in cattle, these differences were not associated with a reduced ability of the uterus to support conceptus survival or development to Day 14 after embryo transfer on Day 7.

In a follow-on study, we asked whether the endometrium from the uterine horn ipsilateral or contralateral to the CL responds differently to an elongating conceptus. Bagés-Arnal et al. (2019) compared the local response of the ipsilateral and contralateral endometrium to a Day 14 conceptus. Although no differences in gene expression were detected between ipsilateral and contralateral endometrium, the response of the endometrium to a Day 14 conceptus was distinct in each uterine horn. Interestingly, more genes were differentially expressed in the contralateral than in the ipsilateral endometrium after exposure to a conceptus 239 vs. 61 DEG, respectively). Many of the biological processes enriched in the DEG between both horns in response to a conceptus were associated with immune response and response to stimuli. This observation is consistent with the study of Moraes et al. (2018), where relatively few differences were detected in the 
endometrial transcriptome of non-pregnant high-fertile, subfertile and infertile heifers; however, the response of the endometrium from high-fertile and subfertile animals to pregnancy was remarkably different (3422 vs. 1095 DEG, respectively).

These data extend those of Sánchez et al. (2019a) describing temporal changes in the transcriptome of the endometrium ipsilateral and contralateral to the CL during a nonpregnant estrous cycle by describing differential response of the endometrium in both uterine horns to an elongating conceptus. The large difference in the number of DEG between the endometrium ipsilateral and contralateral to the CL in response to a Day 14 conceptus may be related to the differences in $\mathrm{P} 4$ concentrations during the first days after ovulation (Takahashi et al., 2016), since, as mentioned earlier, P4 is one the major regulators of the uterine receptivity through changes in the endometrium transcriptome.

\section{Uterine lumen fluid compositon}

The composition of ULF during the preimplantation period has been extensively studied in sheep (see review by Bazer et al., 2015 and references therein). Data in cattle are more limited although various studies have reported on aspects of ULF composition under various physiological states (Mullen et al., 2012; Faulkner et al., 2013; Forde et al., 2015).

We recently metabolically interrogated ULF flushes on Days 12-14 - the window of conceptus elongation-initiation - from cyclic heifers, either (i) supplemented with P4 on Day 3 post-estrous (high P4 cohort), or (ii) not (normal P4 cohort; physiological control). The former group is an established model of conceptus elongation rate acceleration (Carter et al., 2008; Clemente et al., 2009; O’Hara et al., 2014). Given that conceptus elongation coincides with a period of significant bovine pregnancy loss, our aim was to achieve a better understanding of the biochemical landscape surrounding the peri-elongation conceptus. Over 5000 metabolites were screened for by highthroughput untargeted ultra-high-performance liquid chromatography tandem mass spectroscopy, with 233 consistently identified, clustering within 8 superpathways: amino acids, carbohydrates (Simintiras et al., 2019a), lipids (Simintiras et al., 2019b), cofactors, vitamins, nucleotides, peptides, energy substrates, and xenobiotics (Simintiras et al., 2019c). A global analysis of this dataset revealed three core 'strategies' likely utilised by the bovine endometrium to facilitate conceptus elongation, discussed below.

Firstly, indicative of the changing biochemical requirements of the conceptus around the initiation of elongation, a metabolic shift in the ULF of normal P4 heifers after Day 12 was observed (Simintiras et al., 2019d), to which fructose and mannitol/sorbitol were central. More specifically, only these two metabolites increased on Days 13 and 14 vs. 12 within the normal P4 group. Moreover, fructose and mannitol/sorbitol were elevated by 18.4 and 28.4-fold, respectively, in the ULF of high vs. normal P4 heifers on Day 12
(Simintiras et al., 2019a) - the greatest differences observed throughout the study - suggestive of a key role for these metabolites in sustaining, in addition to initiating, conceptus elongation.

Secondly, sub-pathway enrichment and representation analyses revealed that metabolic cascades of likely importance to conceptus elongation-initiation revolve around phospholipids, polyamines, and purines. Regarding the former, membrane biogenesis is intuitively essential to the $\sim 30$-fold increase in trophoblast length between Days 12-15 (Betteridge et al., 1980; Brooks et al., 2014). As 47\% of identified lipids were intricately linked to membrane biogenesis, it seems reasonable to suspect that endometrial lipid secretions contribute to conceptus membrane fusion, and, thus, elongating conceptus membrane biogenesis is not entirely de novo (Simintiras et al., 2019b). The latter, polyamines and purines, are discussed below within the context of adenosine monophosphate signaling.

Thirdly, P4 supplementation amplified the total mean metabolite abundance on Day 14 ( $\mathrm{P} \leq 0.0001)$; however, just 19 metabolites (8.2\% of total) were elevated $(\mathrm{P} \leq 0.05)$ on Day 14 in high vs. normal P4 heifers, and are, therefore, largely responsible for raising the mean (Simintiras et al., 2019d). The biochemical properties of the these 'selectively' amplified 19 metabolites - including glucose (primary fuel source), trimethylamine-N-oxide (proteinstabilizing osmolyte), and phenol sulfate (relatively metabolically inert yet acidic molecule) - (i) support the notion that optimal conceptus elongation is contingent on biophysical and physicochemical, in addition to metabolic, cues, and (ii) contribute to the generation of our hypothesis pertinent to the molecular bases of conceptus elongation initiation, discussed below.

These findings combined, coupled with previous data on the enzymatic profile of bovine ULF (Muñoz et al., 2012; Forde et al., 2014), give rise to the hypothesis that conceptus elongation internally hinges on 5 ' adenosine monophosphate-activated protein kinase (AMPK) and peroxisome proliferator-activated receptor gamma (PPAR $\gamma$ ) activity, and is modulated by glucose, adenine, and adenosine mono- (AMP), di- (ADP), and tri-phosphate (AMP) influx (discussed in Simintiras et al., 2019d). Additional observations worth highlighting include: (i) that total ULF metabolite abundance (Fig. 2A) is not indicative of activity in terms of total day effects (Fig. 2B), P4 effects (Fig. 2C), or day by P4 interactions (Fig. 2D), and (ii) the identification of a plethora of microbiome-associated molecules in ULF, some of which were responsive to P4 (Simintiras et al., 2019c), highlights a need for further research into the influence of the uterine microbiome in uterine metabolism and maternal-embryo communication.

\section{Conclusion}

The period of early embryo development and pregnancy establishment is fascinating. This complex process encompasses ovulation, fertilization, blastocyst formation and growth into an elongated conceptus, 
pregnancy recognition signalling, and development of the embryo and placenta. Despite the aforementioned advances in the field, there is still much to learn. The precise drivers of conceptus elongation remain unknown. While the process is dependent on the uterus - it does not occur in vitro - there is significant variation exhibited amongst conceptuses which is independent of the uterus and may point to variation in oocyte and early embryo quality. Furthermore, the role of the sire in determining embryo quality and in conceptus development is only beginning to be appreciated (Ortega et al., 2018).
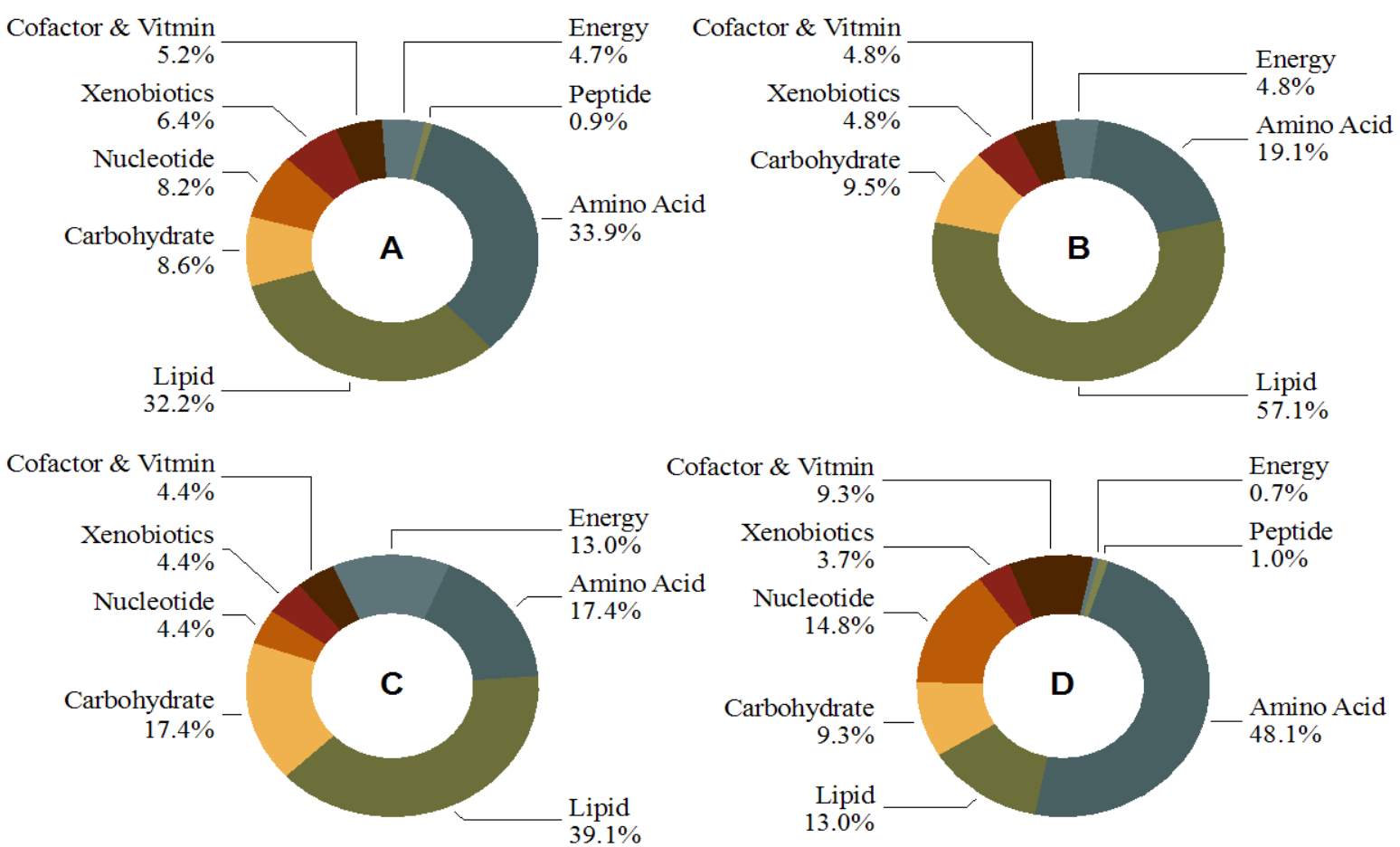

Figure 2. Breakdown of metabolites identified in uterine luminal fluid, by super-pathway, on Days 12-14 of cyclic heifers in terms of total: (A) abundance, (B) day effects, (C) progesterone (P4) effects, and (D) day by P4 interactions. Adapted from Simintiras et al. (2019d).

\section{Author contributions}

All authors (JMS, CAS, PL) contributed to the writing and revising of the manuscript.

\section{Conflict of interest}

Authors declare no conflicts of interest.

Acknowledgments and Funding disclosure statement

This work was supported by grants from Science Foundation Ireland (to PL; Grant number: 13/IA/1983), an Irish Research Council Government of Ireland Postdoctoral Fellowship (to CAS; grant number GIOPD/2017/942), and a University College Dublin Career Development Award (to CAS; Grant number: CDA54580).

\section{References}

Ashworth CJ, Sales DI, Wilmut I. 1989. Evidence of an association between the survival of embryos and the periovulatory plasma progesterone concentration in the ewe. J Reprod Fertil, 87:23-32.

Barnwell CV, Farin PW, Ashwell CM, Farmer WT, Galphin SP, Farin CE. 2016. Differences in mRNA populations of short and long bovine conceptuses on Day 15 of gestation. Mol Reprod Dev, 83:424-441.

Bartol FF, Roberts RM, Bazer FW, Lewis GS, Godkin JD, Thatcher WW. 1985. Characterization of proteins produced in vitro by periattachment bovine conceptuses. Biol Reprod, 32:681-693.

Bauersachs S, Ulbrich SE, Zakhartchenko V, Minten M, Reichenbach M, Reichenbach H-D, Blum H, Spencer TE, Wolf E. 2009. The endometrium responds differently to cloned versus fertilized embryos. Proc Natl Acad Sci USA, 106:5681-5686.

Bauersachs S, Ulbrich SE, Reichenbach HD, Reichenbach M, Büttner M, Meyer HH, Spencer TE, Minten M, Sax G, Winter G, Wolf E. 2012. Comparison of the effects of early pregnancy with human interferon, alpha 2 (IFNA2), on gene expression in bovine endometrium. Biol Reprod, 29:86(2):46. Doi: 10.1095/biolreprod.111.094771.

Bagés-Arnal S, Sánchez JM, Fernández-Fuertes B, McDonald M, Behura SK, Spencer TE, Fair T, 
Lonergan P. 2019. Differential response of bovine endometrium ipsilateral and contralateral to the corpus luteum to a Day 14 conceptus. Annual Meeting of the Society for the Study of Reproduction, San Jose, CA, USA, July 2019.

Bazer FW, Wang X, Johnson GA, Wu G. 2015. Select nutrients and their effects on conceptus development in mammals. Anim Nutr, 1(3):85-95. Doi: 10.1016/j.aninu.2015.07.005.

Bazer FW, Thatcher WW. 2017. Chronicling the discovery of interferon tau. Reproduction, 154:F11-F20. Brandão DO, Maddox-Hyttel P, Løvendahl P, Rumpf R, Stringfellow D, Callesen H. 2004. Post hatching development: a novel system for extended in vitro culture of bovine embryos. Biol Reprod, 71:20482055.

Betteridge K, Eaglesome M, Randall GCB, Mitchell D. 1980. Collection, description and transfer of embryos from cattle 10-16 days after oestrus. J Reprod Fertil, 59:205-216.

Borges AM, Healey GD, Sheldon IM. 2012. Explants of intact endometrium to model bovine innate immunity and inflammation ex vivo. Am J Reprod Immunol, 67:526-539.

Brooks K, Burns G, Spencer TE. 2014. Conceptus elongation in ruminants: Roles of progesterone, prostaglandin, interferon tau and cortisol. J Anim Sci Biotechnol, 5:1-12.

Carter F, Forde N, Duffy P, Wade M, Fair T, Crowe MA, Evans ACO, Kenny DA, Roche JF, Lonergan P. 2008. Effect of increasing progesterone concentration from Day 3 of pregnancy on subsequent embryo survival and development in beef heifers. Reprod Fertil Dev, 20:368-375.

Christie WB, Newcomb R, Rowson LE. 1979. Embryo survival in heifers after transfer of an egg to the uterine horn contralateral to the corpus luteum and the effect of treatments with progesterone or hCG on pregnancy rates. J Reprod Fertil, 56:701-706.

Clemente M, de La Fuente J, Fair T, Al Naib A, Gutierrez-Adan A, Roche JF, Rizos D, Lonergan P. 2009. Progesterone and conceptus elongation in cattle: a direct effect on the embryo or an indirect effect via the endometrium? Reproduction, 138:507-517.

Faulkner S, Elia G, O' Boyle P, Dunn M, Morris D. 2013. Composition of the bovine uterine proteome is associated with stage of cycle and concentration of systemic progesterone. Proteomics, 13:3333-3353.

Forde N, Carter F, Fair T, Crowe MA, Evans ACO, Spencer TE, Bazer FW, McBride R, Boland MP, O'Gaora P, Lonergan P, Roche JF. 2009. Progesterone-regulated changes in endometrial gene expression contribute to advanced conceptus development in cattle. Biol Reprod, 81:784-794.

Forde N, Carter F, Spencer TE, Bazer FW, Sandra O, Mansouri-Attia N, Okumu LA, McGettigan PA, Mehta JP, McBride R, O'Gaora P, Roche JF, Lonergan P. 2011. Conceptus-Induced Changes in the Endometrial Transcriptome: How Soon Does the Cow Know She Is Pregnant? Biol Reprod, 85:144-156.

Forde N, Lonergan P. 2012. Transcriptomic analysis of the bovine endometrium: What is required to establish uterine receptivity to implantation in cattle? $J$ Reprod Dev, 58(2):189-95.

Forde N, Mehta JP, Minten M, Crowe MA, Roche JF, Spencer TE, Lonergan P. 2012. Effects of low progesterone on the endometrial transcriptome in cattle. Biol Reprod, 87:124.

Forde N, McGettigan PA, Mehta JP, O'Hara L, Mamo S, Bazer FW, Spencer TE, Lonergan P. 2014. Proteomic analysis of uterine fluid during the preimplantation period of pregnancy in cattle. Reproduction, 147:575-587.

Forde N, Bazer FW, Spencer TE, Lonergan P. 2015. 'Conceptualizing' the endometrium: identification of conceptus-derived proteins during early pregnancy in cattle. Biol Reprod, 92:156.

Forde N, Lonergan P. 2017. Interferon-tau and fertility in ruminants. Reproduction, 154:F33-F43.

Gad A, Hoelker M, Besenfelder U, Havlicek V, Cinar U, Rings F, Held E, Dufort I, Sirard MA, Schellander K, Tesfaye D. 2012. Molecular mechanisms and pathways involved in bovine embryonic genome activation and their regulation by alternative in vivo and in vitro culture conditions. Biol Reprod, 87:100.

Geary TW, Burns GW, Moraes JG, Moss JI, Denicol AC, Dobbs KB, Ortega MS, Hansen PJ, Wehrman ME, Neibergs H, O'Neil E, Behura S, Spencer TE. 2016. Identification of Beef Heifers with Superior Uterine Capacity for Pregnancy. Biol Reprod, 95(2):47. Doi: 10.1095/biolreprod.116.141390.

Gómez E, Sánchez-Calabuig MJ, Martin D, Carrocera S, Murillo A, Correia-Alvarez E, Herrero P, Canela N, Gutiérrez-Adán A, Ulbrich S, Muñoz M. 2018. In vitro cultured bovine endometrial cells recognize embryonic sex. Theriogenology, 108:176-184.

Gray CA, Burghardt RC, Johnson GA, Bazer FW, Spencer TE. 2002. Evidence that absence of endometrial gland secretions in uterine gland knockout ewes compromises conceptus survival and elongation. Reproduction, 124:289-300.

Hasler JF, Henderson WB, Hurtgen PJ, Jin ZQ, McCauley AD, Mower SA, Neely B, Shuey LS, Stokes JE, Trimmer SA. 1995. Production, freezing and transfer of bovine IVF embryos and subsequent calving results. Theriogenology, 43:141-152.

Kimura K, Matsuyama S. 2014. Successful Nonsurgical Transfer of Bovine Elongating Conceptuses and Its Application to Sexing. J Reprod Dev, 60:210-215.

Lonergan P, Rizos D, Kanka J, Nemcova L, Mbaye AM, Kingston $M$, Wade $M$, Duffy $P$, Boland MP. 2003a. Temporal sensitivity of bovine embryos to culture environment after fertilization and the implications for blastocyst quality. Reproduction, 126:337-346

Lonergan P, Rizos D, Gutierrez-Adan A, Moreira PM, Pintado B, de la Fuente J, Boland MP. 2003b. Temporal divergence in the pattern of messenger RNA expression in bovine embryos cultured from the zygote to blastocyst stage in vitro or in vivo. Biol Reprod, 69:1424-1431.

Lonergan P, Forde N, Spencer T. 2016. The role of progesterone in embryo development in cattle. Reprod 
Fertil Dev, 28:66-74.

Mann GE, Lamming GE. 2001. Relationship between maternal endocrine environment, early embryo development and inhibition of the luteolytic mechanism in cows. Reproduction, 121:175-180.

Mansouri-Attia N, Sandra O, Aubert J, Degrelle S, Everts RE, Giraud-Delville C, Heyman Y, Galio L, Hue I, Yang X, Tian XC, Lewin HA, Renard JP. 2009. Endometrium as an early sensor of in vitro embryo manipulation technologies. Proc Natl Acad Sci USA, 106:5687-5692.

Mathew DJ, Sánchez JM, Passaro, Charpigny G, Behura S, Spencer TE, Lonergan P. 2019. Interferon tau (IFNT)-dependent and -independent effects of the bovine conceptus on the endometrium during early pregnancy. Biol Reprod, 100:365-380.

McMillan WH, Donnison MJ. 1999. Understanding maternal contributions to fertility in recipient cattle: development of herds with contrasting pregnancy rates. Anim Reprod Sci, 57:127-140

McNeill RE, Diskin MG, Sreenan JM, Morris DG. 2006. Associations between milk progesterone concentration on different days and with embryo survival during the early luteal phase in dairy cows. Theriogenology, 65:1435-1441.

Moraes JGN, Behura SK, Geary TW, Hansen PJ, Neibergs HL, Spencer TE. 2018. Uterine influences on conceptus development in fertility-classified animals. Proc Natl Acad Sci USA, 115:E1749-E1758.

Mullen MP, Elia G, Hilliard M, Parr MH, Diskin MG, Evans AC, Crowe MA. 2012. Proteomic characterization of histotroph during the preimplantation phase of the estrous cycle in cattle. $J$ Proteome Res, 11:3004-3018.

Muñoz M, Corrales FJ, Caamaño JN, Díez C, Trigal B, Mora MI, Martín D, Carrocera S, Gómez E. 2012. Proteome of the early embryo-maternal dialogue in the cattle uterus. J Proteome Res, 11:751-766.

O'Hara L, Forde N, Kelly AK, Lonergan P. 2014. Effect of bovine blastocyst size at embryo transfer on day 7 on conceptus length on day 14: Can supplementary progesterone rescue small embryos? Theriogenology, 81:1123-1128.

Okumu LA, Forde N, Fahey AG, Fitzpatrick E, Roche JF, Crowe MA, Lonergan P. 2010. The effect of elevated progesterone and pregnancy status on mRNA expression and localisation of progesterone and oestrogen receptors in the bovine uterus. Reproduction, 140:143-53.

Ortega MS, Moraes JGN, Patterson DJ, Smith MF, Behura SK, Poock S, Spencer TE. 2018. Influences of sire conception rate on pregnancy establishment in dairy cattle. Biol Reprod, 99:1244-1254.

Passaro C, Tutt D, Mathew DJ, Sánchez JM, Browne JA, Boe-Hansen GB, Fair T, Lonergan $P$. 2018. Blastocyst-induced changes in the bovine endometrial transcriptome. Reproduction, 156:219-229.

Passaro C, Tutt D, Bages-Arnal S, Maicas C, LagunaBarraza R, Gutierrez-Adan A, Browne JA, Rath D, Behura SK, Spencer TE, Fair T, Lonergan P. 2019. Global transcriptomic response of bovine endometrium to blastocyst stage embryos. Reproduction. In press.
Rizos D, Fair T, Papadopoulos S, Boland MP, Lonergan P. 2002a. Developmental, qualitative, and ultrastructural differences between ovine and bovine embryos produced in vivo or in vitro. Mol Reprod Dev, 62:320-327.

Rizos D, Ward F, Duffy P, Boland MP, Lonergan P. 2002b. Consequences of bovine oocyte maturation, fertilization or early embryo development in vitro versus in vivo: implications for blastocyst yield and blastocyst quality. Mol Reprod Dev, 61:234-248.

Rizos D, Scully S, Kelly AK, Ealy AD, Moros R, Duffy P, Al Naib A, Forde N, Lonergan P. 2012. Effects of human chorionic gonadotrophin administration on day 5 after oestrus on corpus luteum characteristics, circulating progesterone and conceptus elongation in cattle. Reprod Fertil Dev, 24:472-481.

Sánchez JM, Passaro C, Forde N, Browne JA, Behura SK, Fernández-Fuertes B, Mathew DJ, Kelly AK, Butler ST, Spencer TE, Lonergan P. 2019a. Do differences in the endometrial transcriptome between uterine horns ipsilateral and contralateral to the corpus luteum influence conceptus development to Day 14 in cattle? Biol Reprod, 100:86-100.

Sánchez JM, Mathew DJ, Behura SK, Passaro C, Charpigny G, Butler ST, Spencer TE, Lonergan P. 2019b. Bovine endometrium responds differentially to age-matched short and long conceptuses $†$. Biol Reprod, 101(1):26-39. Doi: 10.1093/biolre/ioz060.

Sartori R, Bastos MR, Wiltbank MC. 2010. Factors affecting fertilisation and early embryo quality in single- and superovulated dairy cattle. Reprod Fertil Dev, 22:151-158.

Satterfield MC, Bazer FW, Spencer TE. 2006. Progesterone regulation of preimplantation conceptus growth and galectin 15 (LGALS15) in the ovine uterus. Biol Reprod, 75:289-96.

Simintiras CA, Sánchez JM, McDonald M, Martins T, Binelli M, Lonergan P. 2019a. Biochemical characterization of progesterone-induced alterations in bovine uterine fluid amino acid and carbohydrate composition during the conceptus elongation window. Biol Reprod, 100:672-685.

Simintiras CA, Sánchez JM, McDonald M, Lonergan P. 2019b. Progesterone alters the bovine uterine fluid lipidome during the period of elongation. Reproduction, 157:399-411.

Simintiras CA, Sánchez JM, McDonald M, Lonergan P. 2019c. The influence of progesterone on bovine uterine fluid energy, nucleotide, vitamin, cofactor, and xenobiotic composition during the conceptus elongationinitiation window. Sci Rep. In press.

Simintiras CA, Sánchez JM, McDonald M, Lonergan P. 2019d. The biochemistry surrounding conceptus elongation. Biol Reprod. In press.

Spencer TE, Forde N, Dorniak P, Hansen TR, Romero JJ, Lonergan P. 2013. Conceptus-derived prostaglandins regulate gene expression in the endometrium prior to pregnancy recognition in ruminants. Reproduction, 146:377-387.

Spencer TE, Forde N, Lonergan P. 2016. The role of progesterone and conceptus-derived factors in uterine biology during early pregnancy in ruminants. J Dairy 
Sci, 99:5941-5950.

Spencer TE, Forde N, Lonergan P. 2017. Insights into conceptus elongation and establishment of pregnancy in ruminants. Reprod Fertil Dev, 29:84-100.

Sponchiado M, Gomes NS, Fontes PK, Martins T, Del Collado M, Pastore A de A, Pugliesi G, Nogueira MFG and Binelli M, Lonergan P. 2017. Pre-hatching embryo-dependent and -independent programming of endometrial function in cattle. PloS One, 12:e0175954.

Stronge AJH, Sreenan JM, Diskin MG, Mee JF, Kenny DA, Morris DG. 2005. Post-insemination milk progesterone concentration and embryo survival in dairy cows. Theriogenology, 64:1212-1224.

Takahashi H, Haneda S, Kayano M, Matsui M. 2016. Differences in progesterone concentrations and mRNA expressions of progesterone receptors in bovine endometrial tissue between the uterine horns ipsilateral and contralateral to the corpus luteum. $J$ Vet Med Sci, 78:613-618.

Talukder AK, Yousef MS, Rashid MB, Awai K,
Acosta TJ, Shimizu T, Okuda K, Shimada M, Imakawa K, Miyamoto A. 2017. Bovine embryo induces an anti-inflammatory response in uterine epithelial cells and immune cells in vitro: possible involvement of interferon tau as an intermediator. $J$ Reprod Dev, 63:425-434.

Viana J. 2018. 2017 Statistics of embryo production and transfer in domestic farm animals. Embryo Technology Newsletter 36:8-25.

Wiltbank MC, Baez GM, Garcia-Guerra A, Toledo MZ, Monteiro PLJ, Melo LF, Ochoa JC, Santos JEP, Sartori R. 2016. Pivotal periods for pregnancy loss during the first trimester of gestation in lactating dairy cows. Theriogenology, 86:239-253.

Wydooghe E, Vandaele L, Heras S, De Sutter P, Deforce D, Peelman L, De Schauwer C and Van Soom A. 2015. Autocrine embryotropins revisited: how do embryos communicate with each other in vitro when cultured in groups? Biol Rev Camb Philos Soc, 92:505520. 